\title{
A Bacia Hidrográfica como unidade geossistêmica e territorial: em questão a Bacia do Parnaíba
}

\author{
The river basin as geosystemic and territorial unit: concerned the Parnaíba Basin
}

\author{
Pessôa $^{1}$, F.S.; Façanha², A.C \\ fabianapessoa28@gmail.com
}

\section{Resumo}

A adoção das bacias hidrográficas como unidade territorial de planejamento e gestão dos recursos hídricos é um modelo de planejamento integrado onde componentes ambientais e sociais são compreendidos no contexto de suas relações sistêmicas. O presente tem por objetivo analisar a concepção geossistêmica como modelo de análise ambiental e nas discussões referentes ao planejamento ambiental na Bacia do Parnaíba. A metodologia que deu suporte a pesquisa foi a bibliográfica primária e secundária. Nesta pesquisa, de forma sucinta, foi possível perceber que apesar da existência da Política Nacional de Recursos hídricos que adota a bacia hidrográfica de unidade territorial de planejamento, a Bacia do Parnaíba ainda não possui um plano de gestão e a dificuldade de elaboração do mesmo é resultado da grande diversidade física, econômica, político-administrativa e social. que propõem ações sobre o mesmo, não garantem uma gestão efetiva.

Palavras-chave: Geossistema, unidade territorial e Bacia do Parnaíba

\begin{abstract}
The adoption of the river basin as the basic unit for planning and management of water resources is an integrated planning model where environmental and social components are understood in the context of its systemic relationships. This aims to analyze the geosystemic design and environmental analysis model and in discussions on environmental planning in the Parnaíba Basin. The methodology that supported the research was the primary and secondary literature. In this research, succinctly, it is noted that despite the existence of the National Policy of Water Resources Adopting the river basin territorial unit of planning, the Parnaíba Basin does not have a management plan and the same development difficulties is result of great physical diversity, economic, political-administrative and social. Proposing actions on it, do not guarantee an effective management.
\end{abstract}

Keywords: Geosystem, territorial unity and the Parnaiba Basin

\section{INTRODUÇÃO}

A atual legislação brasileira de recursos hídricos preconiza a adoção das bacias hidrográficas como unidade territorial de planejamento e gestão destes recursos. Este é um modelo de planejamento integrado onde componentes ambientais e sociais são compreendidos no contexto de suas relações sistêmicas. Este artigo visa analisar a concepção geossistêmica como modelo de análise ambiental e nas discussões referentes ao planejamento ambiental na Bacia do Parnaíba.

A Bacia Hidrográfica do Rio Parnaíba é a maior bacia genuinamente nordestina e uma das mais importantes da Região Nordeste do Brasil abrangendo os estados do Piauí, Ceará e Maranhão. A Bacia do Parnaíba tem como rio principal o Parnaíba, que por sua vez foi responsável pela implantação da capital piauiense, Teresina e também pelo crescimento urbano da 1 Fabiana da Silva Pessoa. Centro de Ciências. Programa de Pós-Graduação em Geografia/Doutoranda. Universidade Federal do Ceará. UFC, 
cidade de Timon, no Maranhão; que juntas somam o maior aglomerado populacional no interior da bacia e as que mais contribuem para a degradação desta.

É notório a relevância de planejar e gerir os recursos hídricos a partir da sensibilização e conscientização da população e dos governantes. O modelo geossistêmico tende a ajustar as atividades humanas ao meio ambiente de forma integrada e participativa para assegurar a recuperação e/ou preservação do mesmo, em especial dos recursos hídricos.

\section{METODOLOGIA}

De maneira geral, os procedimentos iniciais e o desenvolvimento da pesquisa foram integrados por fontes secundárias que corresponde à pesquisa bibliográfica baseada em obras e autores que produziram sobre o tema em estudo. Nesse percurso, fez-se uso de livros, teses, dissertações, relatórios de pesquisas, documentos institucionais, leis, fontes estatísticas e artigos científicos publicados em meios impressos e digitais.

Foi realizada pesquisa bibliográfica, documental e direta que segundo Marconi e Lakatos (2006) é: levantamento de dados do próprio local onde os fenômenos ocorrem através da visita a órgãos públicos e pesquisa de campo. Nessa pesquisa, buscou-se ter acesso a documentos e informações sobre o Rio Parnaíba e Bacia Hidrográfica do Parnaíba, por meio de visitas na Secretaria Estadual de Meio Ambiente e Recursos Hídricos do Piauí (SEMARH), Secretaria Estadual de Meio Ambiente e Recursos Hídricos do Maranhão (SEMA), Secretaria de Planejamento do Piauí (SEPLAN - PI) e Secretaria de Planejamento do Maranhão (SEPLAN - MA), no Instituto Brasileiro de Meio Ambiente e Recursos Renováveis (IBAMA), na Companhia de Desenvolvimento dos Vales do Rio São Francisco e do Rio Parnaíba (CODEVASF) e na Região Integrada de Desenvolvimento da Grande Teresina (RIDE).

Outro método utilizado foi o auxílio de geotecnologias e softwares como o Arcgis 10.1 para a organização de dados e elaboração de mapas.

\section{RESULTADOS E DISCUSSÃO}

Segundo Guerra (1978, p. 48), a bacia hidrográfica é definida como "um conjunto de terras drenadas por um rio principal e seus afluentes". No entanto, inúmeros autores não apresentam os limites internos do sistema de uma bacia hidrográfica, por esta não possuir dimensões fixas. Por esta razão, a bacia hidrográfica, também, pode ser definida como:

[...] um sistema que compreende um volume de materiais, predominantemente sólidos e líquidos, próximos à superfície terrestre, delimitado interno e externamente por todos os 
processos que, a partir do fornecimento de água pela atmosfera, interferem no fluxo de matéria e de energia de um rio ou de uma rede de canais fluviais. Inclui, portanto, todos os espaços de circulação, armazenamento, e de saídas de água e do material por ela transportado, que mantêm relações com esses canais (RODRIGUES e ADAMI, 2005, p. 147-148).

Todos os rios que compõem uma bacia hidrográfica formam uma rede hidrográfica, esta por sua vez é constituída por rios hierarquicamente interligados. Cada bacia hidrográfica se interliga com outra de ordem hierárquica superior, constituindo, em relação à última, uma sub-bacia.

De acordo com Fernandes e Silva (1994), a subdivisão de uma bacia hidrográfica de maior ordem em sub-bacias permite a pontualização de problemas difusos, tornando mais fácil a identificação de focos de degradação de recursos naturais, da natureza dos processos de degradação ambiental instalados e o grau de comprometimento da produção sustentada existente.

Segundo Fernandes e Silva (1994), as bacias hidrográficas constituem ecossistemas adequados para avaliação dos impactos causados pela atividade antrópica que podem acarretar riscos ao equilíbrio e à manutenção quantitativa e qualitativa da água, uma vez que estas variáveis são relacionadas com o uso do solo.

A bacia hidrográfica é o palco das ações e degradações ocasionadas pela ação do homem e reflete todos efeitos destas ações. É nesta perspectiva que a bacia se apresenta como unidade geossistêmica $^{3}$ e também como unidade territorial de planejamento e gestão ambiental, incluindo os recursos hídricos, apresentados na perspectiva geográfica.

A geografia é uma ciência que tem como objeto de estudo o espaço. A palavra espaço ${ }^{4}$ por si só, não expressa a real especificidade geográfica, mas a organização desse espaço traz uma noção mais identificadora. Segundo Santos (1996), a organização do espaço reflete de forma implícita a dinâmica relação entre os sistemas de objetos e os sistemas de ações ${ }^{5}$ construídas pelas sociedades que o detêm. Sob esta óptica é correto afirmar que o espaço geográfico é concreto e a delimitação de sua área é necessária para estudo. Segundo Lima (2005, p.174)

3 Unidade Geossistêmica é um modelo de análise baseada na Teoria Geral dos Sistemas proposta por Ludwig Von Bertalanffy em 1901. No âmbito da Geografia física o "geossistema" foi proposto por Sotchava (1960) e Bertrand (1972) a partir da ideia de equilíbrio na natureza e da existência de ajustes recíprocos entre sistemas, subsistemas e entre suas variáveis. A perspectiva é de que há uma relação espaço-tempo compatível com a escala sócio econômica enfocando os fatores biogeográficos e socioeconômicos.

4 Espaço ou Espaço Geográfico é o objeto de estudo da Ciência Geográfica e define-se como o contínuo resultado das relações sócioespaciais, são elas: econômicas, políticas e simbólico-culturais.

5 Segundo Milton Santos o espaço é definido como um conjunto indissociável de sistemas de objetos e sistemas de ações. De um lado, os sistemas de objetos condicionam a forma como se dão as ações, e de outro lado, os sistemas de ações leva a criação de objetos novos ou se realiza sobre objetos preexistentes, ou seja, o sistema de objetos corresponde a um conjunto de forças produtivas e o sistema de ações corresponde ao conjunto das relações sociais de produção. 
A delimitação de um espaço possuidor de características próprias estava no escopo da Geografia desde sua fase inicial e hoje, em qualquer estudo que se faça, a primeira preocupação é definir o recorte espacial. Esse recorte, além de ser uma necessidade prática de operacionalização da pesquisa, não deve ser arbitrário, pois é uma necessidade metodológica estreitamente relacionada aos pressupostos teóricos adotados.

O recorte espacial permitirá a definição da abordagem de uma pesquisa, a extensão das análises e a validade das observações. Considerando os recortes a partir da identificação de um conjunto de objetos inter-relacionados por uma lógica constitutiva, a bacia hidrográfica se apresenta como um recorte natural adequado para a análise de um sistema antropizado que são responsáveis pela dinâmica da bacia e se apresenta como recorte essencial diante da questão ambiental.

O modelo geossistêmico é um método de análise que surgiu na segunda metade do século $\mathrm{XX}$ com o objetivo de tratar o meio ambiente na geografia de forma integrada. Na visão geossitêmica, o recorte da bacia hidrográfica, apesar de apresentar-se como um recorte natural, não desconsidera o elemento social desde que ele seja considerado como um elemento a mais no sistema. Lima (2005, p.176) afirma que "a inserção do aspecto humano pode ser feita de um modo que sua ação seja vista como de mais uma espécie viva envolvida no equilíbrio ou desequilíbrio do sistema natural”.

À luz dessa concepção é compreensível que a organização do espaço é algo complexo que envolve determinações sociais e naturais, e a bacia hidrográfica se apresenta como palco dessas ações e degradações que se apresentam de forma sistemática. Na visão geossistêmica, a bacia se identifica como um recorte capaz de unificar os processos ambientais e as interferências humanas tem conduzido à aplicação do conceito de gestão de bacias hidrográficas em um novo panorama.

Mediante a influência da perspectiva geossistêmica a bacia hidrográfica, na atualidade, é vista como unidade territorial de planejamento e gestão dos recursos hídricos, pois a partir do recorte da bacia pode ser dado a elas um significado de identidade ou unidade territorial.

O conceito de unidade territorial está relacionado a ordenamento do território que por sua vez é uma política de Estado e um instrumento de planejamento, que permite uma apropriada organização político-administrativa do país e a projeção espacial das políticas de desenvolvimento social, econômico, ambiental e cultural da sociedade (BECKER, 2005). Sob essa conjuntura é pertinente afirmar que o território é o espaço onde se encontram as relações de poder, no qual atores locais/regionais buscam atender as suas demandas e necessidades. O Estado deve aparecer com a função de controle, construindo e legislando políticas regulatórias. Neste sentido, Moraes (2005, p.43) define território:

O território é uma materialidade terrestre que abriga o patrimônio natural de um país, suas estruturas de produção e os espaços de reprodução da sociedade (lato sensu). São nele que se alocam as fontes e os estoques de recursos naturais disponíveis para uma dada sociedade 
e também os recursos ambientais existentes. E é nele que se acumulam as formas espaciais criadas pela sociedade ao longo do tempo (o espaço produzido). Tais formas se agregam ao solo onde foram construídas, tornando-se estruturas territoriais, condições de produção e reprodução em cada conjuntura considerada.

A partir da definição de Moraes (2005), a bacia hidrográfica como unidade territorial ${ }^{6}$ pode ser entendida como o espaço da prática e também um produto da prática social. É nesta perspectiva que diversos autores adotam a bacia hidrográfica como uma unidade territorial adequada para o planejamento e gestão do território, por possibilitar uma análise integrada entre os elementos dos meios físico, biológico e antrópico.

Segundo Albuquerque (2012), a delimitação das bacias hidrográficas é essencial para a gestão dos recursos e intervenção do Estado. A partir desta delimitação o poder público e a sociedade civil adquirem maior capacidade de organização e direcionamento de esforços, reconhecimento dos diversos níveis de demandas específicas e formulação de políticas na área dos recursos hídricos.

A atual proposta de Gestão dos Recursos Hídricos em vigor, a Lei Federal n. . 9433/97, instituiu a Política Nacional de Recursos Hídricos e criou o Sistema Nacional de Gerenciamento de Recursos Hídricos - SINGREH. A proposta dessa lei é fornecer instrumentos legais para disciplinar tanto a apropriação, como os múltiplos usos das águas territoriais.

A Política Nacional de Recursos Hídricos consolidou a gestão participativa nas bacias hidrográficas, limitando a atuação dos detentores de seu domínio e transferindo uma parcela do poder de decisão aos usuários da água e à sociedade civil. Trata-se de uma organização integrada inserindo todos os atores integrantes do sistema nacional de gerenciamento de recursos hídricos, tanto na coordenação das ações e planos, quanto na descentralização da execução. A gestão dos recursos hídricos mostra se necessariamente descentralizada e conta com a participação do poder público, dos usuários e das comunidades.

A bacia hidrográfica é a unidade de gestão e a efetiva implementação da Política Nacional de Recursos Hídricos de forma descentralizada, participativa, integrada e compartilhada que deverá ser garantida pelo Conselho Nacional de Recursos Hídricos - CNRH e planejada pelo Comitê de Bacia Hidrográfica e integrada a Agência de Água.

\footnotetext{
6 Utilizando o conceito de bacia hidrográfica ligado ao conceito de território, a professora Adoréa Albuquerque na publicação intitulada "Bacia Hidrográfica: unidade de planejamento Ambiental" considera a bacia hidrográfica como unidade territorial para fins de planejamento ambiental, adotando uma visão estratégica desse espaço de forma integrada.
} 
A Bacia Hidrográfica do Rio Parnaíba é a maior bacia genuinamente nordestina e uma das mais importantes da Região Nordeste do Brasil, ficando atrás apenas da Bacia do Rio São Francisco. A Bacia do Parnaíba se estende pelos Estados do Ceará, Piauí e Maranhão entre as coordenadas $02^{\circ} 21^{\prime} \mathrm{S}$ e $11^{\circ} 06^{\prime} \mathrm{S}$ de latitude e $47^{\circ} 21^{\prime} \mathrm{W}$ e $39^{\circ} 44^{\prime} \mathrm{W}$ de longitude compreendendo uma área de aproximadamente $331.441 \mathrm{~km}^{2}$, sendo $249.497 \mathrm{~km}^{2}$ no Piauí, $65.492 \mathrm{~km}^{2}$ no Maranhão, 13.690 km² no Ceará e 2.762 km² de área em litígio entre Piauí e Ceará (MMA, 2006).

Dentre a área total da Bacia do Parnaíba, 75,73\% estão localizados no Piauí, 19,02\% no Maranhão e 4,35\% no Ceará (CODEVASF, 2006). Conforme a Avaliação Ambiental Integrada da Bacia do Rio Parnaíba (AAI), a Bacia abrange cerca de 3,9\% do território nacional e drena quase a totalidade do estado do Piauí (99\%), parte do Maranhão (19\%) e Ceará (10\%), como se observa na Figura 01.

Segundo a CODEVASF (2014) a Bacia do Parnaíba abriga 4,8 milhões de pessoas, 279 municípios e três biomas diferentes: o Cerrado, a Caatinga e o Costeiro. Dos municípios, 240 então inseridos totalmente no interior da bacia e os demais 39 encontram-se parcialmente na bacia, os quais seus territórios extrapolam os limites da bacia.

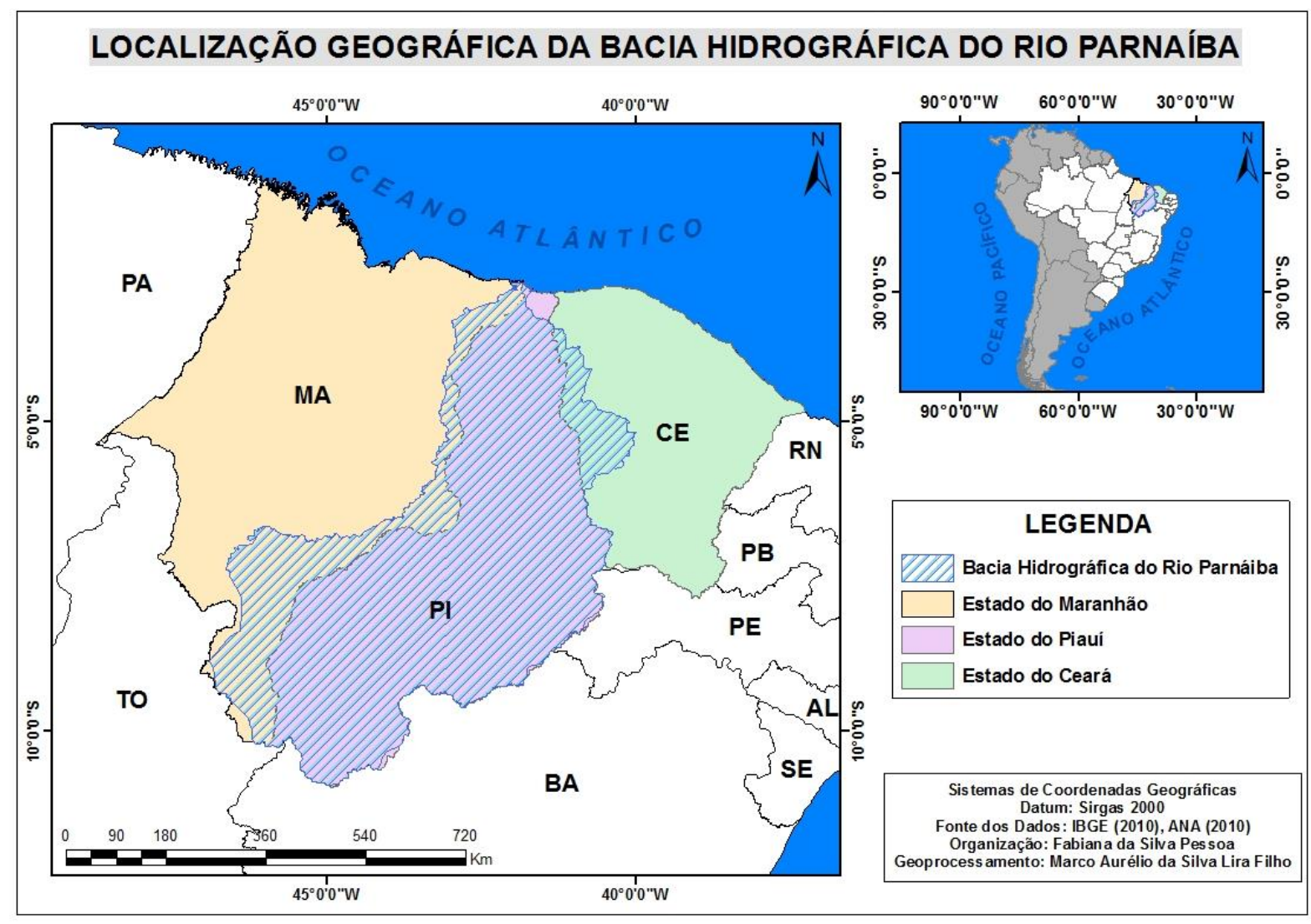

Figura 01- Localização da Bacia do Parnaíba em relação aos Estados integrantes.

Fonte: IBGE (2010) e ANA (2010). Pessoa, 2015; Geoprocessamento Lira Filho, 2015. 
Conforme a ANA (2013), a Bacia Hidrográfica do Parnaíba é hidrologicamente a segunda mais importante da Região Nordeste. Sua bacia hidrográfica é a mais extensa dentre as 25 bacias do Nordeste, no entanto, apresenta grandes diferenças inter-regionais tanto em termos de desenvolvimento econômico e social quanto em relação a disponibilidade hídrica.

Mediante essas diferenças, a Bacia do Parnaíba foi dividida em três grandes sub-bacias: Alto, Médio e Baixo Parnaíba. O Alto Parnaíba tem sua vegetação, em geral, constituído pelo cerrado. Neste destaca-se além do Parnaíba, o rio principal, os afluentes Rio Balsas, no Maranhão, e Uruçuí Vermelho, Uruçuí Preto, Gurgueia e Itaueira, no Piauí. Na atualidade, a área que abrange a sub-bacia do Alto Parnaíba é em grande parte ocupada pela produção de grãos com destaque para a soja (CODEVASF, 2014).

Na sub-bacia do Médio Parnaíba a vegetação predominante é a Caatinga, contudo também há ocorrência de cerrado. Nesta os principais afluentes do Parnaíba são os rios Canindé, cujas suas nascentes encontram-se em território piauiense, e Poti que nasce em território cearense; e se destaca por compreender a área com maior densidade demográfica, a capital do Estado do Piauí. A subbacia do Baixo Parnaíba é marcada pela presença da caatinga e da vegetação costeira. O Rio Longá é o principal afluente do Parnaíba nesta sub-bacia, onde a agricultura e o turismo se destacam como principais atividades econômicas (CODEVASF, 2014).

As sub-bacias do Alto, Médio e Baixo Parnaíba são divididas em bacias menores conforme mostra o Figura 02, onde são apresentadas as sub divisões das sub-bacias juntamente com seus valores em relação à área de cada Estado integrante.

\begin{tabular}{|c|c|c|c|c|c|c|c|}
\hline \multirow{3}{*}{ Sub 1} & \multirow{3}{*}{ Sub 2} & \multirow{3}{*}{ Rio Principal } & \multicolumn{4}{|c|}{ Estado / Área } & \multirow[b]{2}{*}{ Area Total } \\
\hline & & & Ceará & Maranhio & Piaui & $\begin{array}{c}\text { Litigio } \\
\text { Ceara/Piaui }\end{array}$ & \\
\hline & & & $\left(\mathrm{Km}^{\mathrm{H}}\right)$ & $\left(\mathrm{Km}^{2}\right)$ & $\left(\mathrm{Km}^{2}\right)$ & $\left(\mathrm{Km}^{2}\right)$ & $\left(\mathrm{Km}^{2}\right)$ \\
\hline \multirow{4}{*}{ Alto Parnaiba } & Parnaiba 01 & Balsas & & $25.570,6$ & & & $25.578,3$ \\
\hline & Parnaiba 02 & Alto Parnaiba & & $21.915,0$ & $37.119,8$ & & $59.052,6$ \\
\hline & Parnaiba 03 & Garguéia & & 159,0 & $52.140,5$ & & $52.315,3$ \\
\hline & Parnaiba 04 & Itaueiras & & $2.257,2$ & $12.468,3$ & & $14.729,9$ \\
\hline \multirow{2}{*}{ Médio Parnaiba } & Parnaiba os & Piauy/Caninde & & & $75.067,2$ & & $75.089,9$ \\
\hline & Parnaiba 06 & Poti/Parnafiba & $12.121,2$ & $6.179,4$ & $41.667,8$ & $1.965,2$ & $61.951,7$ \\
\hline Baixo Parnaiba & Parnaiba 07 & Longa/Parnaiba & $1.568,9$ & $9.410,5$ & $31.033,7$ & 797,3 & $42.823,1$ \\
\hline Total & & & $13.690,1$ & $65.491,7$ & $249.497,2$ & $2.762,4$ & $331.441,5$ \\
\hline
\end{tabular}

Figura 02-Relação das Sub-bacias da Bacia Hidrográfica do Parnaíba e Estados integrantes.

Fonte: MMA (2006) 
A configuração de uma bacia está relacionada aos seus aspectos geomorfológicos. A Bacia do Parnaíba encontra-se em cerca de $15 \%$ sob escudos cristalinos e $85 \%$ sob a Bacia sedimentar do Parnaíba; quanto a geologia está inserida em três províncias, são elas: do Parnaíba, Borborema e São Francisco do Norte (MMA, 2006).

A disponibilidade hídrica na Bacia do Parnaíba é resultado da relação entre precipitação, vazão e da evapotranspiração. Segundo a ANA (2002) as médias anuais na Bacia do Parnaíba correspondem a $1.117 \mathrm{~mm}$ de precipitação, $763 \mathrm{~m}^{3} / \mathrm{s}$ de vazão e $1.045 \mathrm{~mm}$ de Evapotranspiração, que equivale a 94\%. Contudo, a Bacia sedimentar do Parnaíba possui grande potencialidade de água subterrânea mediante a presença dos aquíferos Cabeças, Serra Grande, Poti-Piauí e Itapecuru.

No que se refere a qualidade das águas da Bacia do Parnaíba, Brasil (2005) afirma que os dados existentes sobre a qualidade das águas superficiais são insuficientes para definir com exatidão tal indicador. Contudo, mediante estimativas da carga poluidora domestica lançado sobre os rios da Bacia, observa-se que os maiores problemas encontram-se nas regiões com maiores aglomerados urbanos como Teresina, Parnaíba, Picos, Piripiri e Crateús (BRASIL, 2005).

De acordo com Câmara, Moura e Oliveira (2002) a Bacia do Parnaíba destaca-se pela extensão e volume, assumindo um papel importante no desenvolvimento da região do seu entorno, principalmente como fonte de alimento e água para abastecimento público e produção de energia hidrelétrica.

De modo geral, é possível afirmar que os aspectos físicos da bacia hidrográfica, as condições climáticas, os aspectos geomorfológicos e o uso/ocupação do solo influenciam na dinâmica e na qualidade dos recursos hídricos, principalmente os superficiais. Todos os elementos e/ou atores que influenciam direta e indiretamente sobre uma bacia estão interligados compondo um sistema ou geossistema.

\section{CONCLUSÃO}

A bacia hidrográfica, no contexto atual, é reconhecida como unidade territorial de planejamento que deve comtemplar relações sociais, processos ambientais e também o planejamento e a gestão de um território. É importante, também, compreender que uma bacia hidrográfica nem sempre coincide com as delimitações político-administrativas, fato que em geral resulta na dificuldade de gerir e articular políticas e ações efetivas na mesma.

O planejamento de uma bacia hidrográfica proposta como unidade territorial de planejamento de recursos hídricos deve compreender a concepção sistêmica que a água não deve ser gerida sem considerar suas inter-relações com os outros componentes do meio como, por exemplo, os solos, a vegetação, o relevo e com a ação antrópica que altera as condições de funcionamento dos 
sistemas naturais, produzindo mudanças que podem afetar diretamente a qualidade e quantidade de água disponível em uma bacia.

A Bacia Hidrográfica do Rio Parnaíba abrange três Estados distintos: Piauí, Maranhão e Ceará; este contexto justifica a dificuldade de planejar e gerir a Bacia do Parnaíba de forma integrada e participativa por todos que a compõe, pois envolve distintas leis e interesses político, econômicos, sociais e de usos e ocupação do solo, além da diversidade física.

\section{REFERÊNCIAS}

ANA (AGÊNCIA NACIONAL DAS ÁGUAS). A Evolução da Gestão dos Recursos Hídricos no Brasil. Brasília, DF, 2002.

- Conjuntura dos Recursos Hídricos no Brasil - Informe 2013. Disponível em:<arquivos.ana.gov.br/institucional/spr/conjuntura/website_relatórioconjuntura/projeto/index.ht ml> Acesso em: 06 Jul. 2016.

ALBUQUERQUE, A. R da C. Bacia hidrográfica: unidade de planejamento ambiental. Revista Geonorte, Edição Especial, v.4, n.4, p.201 -209, 2012.

BECKER, B. K. Síntese geral sobre Política Nacional de Ordenamento Territorial. In: BRASIL. Ministério da Integração Social. Oficina sobre Política Nacional de Ordenamento Territorial. Brasília, DF: MI, 2005.

. Lei $\mathrm{n}^{\circ}$ 9.433, de 8 de janeiro de 1997. Institui a Política Nacional de Recursos Hídricos e cria o Sistema Nacional de Gerenciamento de Recursos Hídricos - SINGREH. Disponível em: < http://www.mma.gov.br/port/conama/legiabre.cfm?codlegi=370> . Acesso em: 25 Jul. 2016.

CÂMARA, F. de M. M.; MOURA, A. do N; OLIVEIRA, M. do C. B. Ficoflórula planctônica do rio Parnaíba, estado do Piauí- Brasil. Revista Nordestina de Biologia. v. 16(1/2), 2002.

COMPANHIA DE DESENVOLVIMENTO DOS VALES DO SÃO FRANCISCO E DO PARNAÍBA. Plano de Ação para o Desenvolvimento Integrado da Bacia do Parnaíba, PLANAP: Atlas da Bacia do Parnaíba - Brasília: TDA Desenho \& Arte Ltda, 2006.

FERNANDES, M.R. e SILVA, J. C. Programa Estadual de Manejo de Sub-Bacias Hidrográficas: Fundamentos e estratégias. Belo Horizonte: EMATERMG, 1994. 24p.

GUERRA, A. T. Dicionário geológico-geomorfológico. Rio de Janeiro: IBGE, 1978.

LAKATOS, E. M; MARCONI, M. A. Fundamentos de metodologia científica. 6. ed. 3. reimpr. São Paulo: Atlas, 2006.

LIMA, A. G. A bacia hidrográfica como recorte de estudos em geografia humana. GEOGRAFIA - v. 14, n. 2, jul./dez. 2005 - Universidade Estadual de Londrina, Departamento de Geociências.

MINISTÉRIO DO MEIO AMBIENTE, Secretaria de Recursos Hídricos. Plano Nacional de Recursos Hídricos. Síntese Executiva. Brasília: MMA, 2006.

MORAES, A.C.R. Ordenamento Territorial: uma conceituação para o planejamento estratégico. In: OFICINA SOBRE A POLÍTICA NACIONAL DE ORDENAMENTO TERRITORIAL, 2003, Brasília. Anais... Brasília: Ministério da Integração Nacional, Secretaria de Políticas de Desenvolvimento Regional, MI, 2005. p. 43-48.

RODRIGUES, C; ADAMI, S. Técnicas fundamentais para o estudo de bacias hidrográficas. In: VENTURI, L. A. B. (org). Praticando Geografia: técnicas de campo e laboratório em geografia e análise ambiental. São Paulo: Oficina de Textos, 2005, p. 147-166.SANTOS, M. 1996. A Natureza do Espaço: Técnica e Tempo. Razão e Emoção. São Paulo: Hucitec.

TERMO DE REFERÊNCIA DA AVALIAÇÃO AMBIENTAL INTEGRADA - AAI dos aproveitamentos hidrelétricos da Bacia do Rio Parnaíba. Julho - 2005. Disponível em < 
http://www.epe.gov.br/MeioAmbiente/Documents/MeioAmbiente_3/AAI\%20Bacia\%20Parnaiba\% 20-\%20Termo\%20de\%20Referencia.pdf> Acesso em: 23 Jul. 2016.

Recebido em: 14/08/2016

Aceito para publicação em: 01/10/2016 